\title{
Concurrent spontaneous pneumothorax in identical twins
}

\author{
A RASHID, A SENDI, A AL-KADHIMI, R J DONNELLY \\ From the Regional Adult Cardiothoracic Unit, Broadgreen Hospital, Liverpool
}

The common cause of simple pneumothorax is rupture of an emphysematous bleb or bulla. The aetiology of these is uncertain. A familial predisposition has previously been suggested $^{1}$ and we report the incidence of concurrent spontaneous pneumothoraces in identical twins. We have found no previous report in the English literature of concurrent spontaneous pneumothorax in identical twins treated subsequently by surgery.

\section{Case report}

A 71 year old man was admitted to Broadgreen Hospital in September 1985 with a third episode of right sided spontaneous pneomothorax. His identical twin brother was returning home after visiting him in hospital when he developed a right sided pneumothorax while standing at the bus stop. He too had had two previous right sided pneumothoraces. These had not previously occurred concurrently in the twins, but all episodes had taken place within the last two years. The first two episodes in both patients had resolved after intercostal intubation. The third episode in each brother was also managed by intercostal drainage with suction, but in both cases the air leak persisted and both underwent thoracotomy. Both twins were moderate smokers of average height and suffered from chronic obstructive airways disease. Their past medical history differed only in that one had had a permanent pacemaker inserted three months previously for complete heart block. The $\alpha_{1}$ antitrypsin concentrations were normal in both patients. At operation the findings in the two brothers were identical. Both right lungs were emphysematous with bullae at the apices of the upper lobes. A small hole was identified in one of these bullae in each patient. Apical bullae were stapled at the base and a parietal pleurectomy was performed. Postoperatively the lungs remained well expanded and both patients were discharged home 11 days after operation.

Address for reprint requests: Mr RJ Donnelly FRCS, Regional Adult Cardiothoracic Unit, Broadgreen Hospital, Liverpool L14 3LB.

Accepted 12 May 1986

\section{Comment}

Familial emphysema has been reported in association with Marfan's syndrome ${ }^{2}$ and bullae formation may occur in association with $\alpha_{1}$ antitrypsin deficiency. ${ }^{3}$ Gibson described three sisters presenting with concurrent spontaneous pneumothoraces and suggested a familial predisposition in these patients. ${ }^{1}$ The sharpness of the inner border of the first or second ribs has also been incriminated as a predisposing factor in the development of spontaneous pneumothorax. ${ }^{4}$ Recurrent pneumothoraces in identical twins necessitating surgical treatment has not previously been reported in English publications so far as we are aware. Worldwide, a literature search showed only one report on this subject. ${ }^{5}$ The twins reported in this paper do not fall into any of the categories described above; and the presence of almost identical timining, clinical picture, and operative findings suggests the possibility that the aetiology is genetically based.

A photograph showing the identical twins convalescing from thoractomy was provided.

\section{References}

1 Gibson GJ. Familial pneumothorax and bullae. Thorax 1977;32:88-90.

2 Bolande RP, Tucker AS. Pulmonary emphysema and other cardiorespiratory lesions as part of the Marfan abiotrophy. Pediatrics 1964;33:356-66.

3 Eriksson S. Studies in alpha 1 antitrypsin deficiency. Acta Med Scand 1965;suppl 432:5-85.

4 Stephenson SF. Spontaneous pneumothorax, the sharp rib syndrome. Thorax 1976;31:369-72.

5 Inoue N, Kitano I, Murakami T. Surgical treatment of spontaneous pneumothorax occurring in monovular twins-report of two cases. Kyobu Geca 1982;35:447-50. 